\title{
Commentary: Surprisingly good results from a complex, lengthy aortic arch technique
}

John A. Elefteriades, MD, PhD(hon), Mohammad A. Zafar, MD, Dimitra Papanikolaou, MD, and Bulat A. Ziganshin, MD, PhD

\author{
From the Aortic Institute at Yale-New Haven Hospital, Yale University School of Medicine, New Haven, Conn. \\ Disclosures: Authors have nothing to disclose with regard to commercial support. \\ Received for publication Oct 20, 2018; accepted for publication Oct 21, 2018; available ahead of print Dec 14, \\ 2018. \\ Address for reprints: John A. Elefteriades, MD, PhD(hon), Aortic Institute at Yale-New Haven Hospital, Yale Uni- \\ versity School of Medicine, Clinic Building CB 317, 789 Howard Ave, New Haven, CT 06519 (E-mail: john. \\ elefteriades@yale.edu). \\ J Thorac Cardiovasc Surg 2019;157:1379-80 \\ $0022-5223 / \$ 36.00$ \\ Copyright $(2018$ by The American Association for Thoracic Surgery \\ https://doi.org/10.1016/j.jtcvs.2018.10.143
}

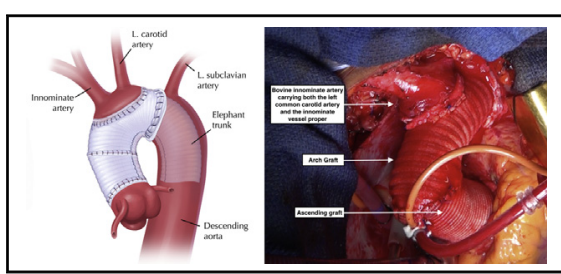

Aortic arch replacement with Carrel patch reimplantation of the bovine innominate artery.

\section{Central Message}

Aortic arch replacement with a 4-branch graft and antegrade cerebral perfusion presents another option for surgeons, but no evidence is presented demonstrating superiority over conventional techniques.

See Article page 1370 .
Minatoya and colleagues ${ }^{1}$ are to be congratulated for their excellent clinical results in applying antegrade cerebral perfusion (ACP) and a 4-branched graft in aortic arch replacement in more than 1000 patients. Hospital mortality was $5.1 \%$, permanent stroke $3.6 \%$, and paraplegia $0 \%$. Midterm survival was good $(81 \%$ and $63 \%$ at 5 and 10 years, respectively). Graft-related complications during follow-up were minimal. The cardiothoracic surgery community is fortunate for the authors' clear documentation of their technique's favorable clinical experience. The authors' technique is closely related to the Sun technique, but with a different anastomotic sequence. ${ }^{2,3}$

Some unusual characteristics of the experience and some negatives deserve noting:

- The rate of concomitant aortic valve repair or replacement was very low (only 6.4\%), lower than expected for such a patient group.

- The rate of concomitant aortic root replacement was low $(3.8 \%)$, again lower than expected.

- There was not a single case of recurrent nerve injury and vocal cord paralysis in the entire series - a remarkable accomplishment.

- The operations were exceedingly long, with an operative time of 8 hours, a cardiopulmonary bypass time of 4.2 hours, an ACP time of 2.6 hours, and a lower body circulatory arrest time of 1 hour. It is surprising that these important lengthy intervals did not exact clinical consequences. We are not certain that the fortunate results in the present study would be seen in general application.
- Superficial temporal artery cannulation was used to monitor brain perfusion pressures. Clinical familiarity with this technique is not widespread.

- Perfusion was performed at rates much lower than conventionally used $(10-20 \mathrm{cc} / \mathrm{kg} / \mathrm{min})^{1}$. This may be a positive because cerebral edema tends to accompany ACP techniques. ${ }^{4,5}$

- The performance of a possibly superfluous anastomosis of the branched graft to the elephant trunk graft is questionable. Operative and perfusion times are already long. It seems this anastomosis could be avoided quite simply by in-folding the branched graft into the descending aorta (a bit cumbersome, but possible) or using a Sienna (ie, skirt) graft with bespoke attachment of the branches before bypass.

It is important to put the clinical methods of the present study into perspective on 2 important points. The simpler Carrel patch technique for great vessel attachment has yielded excellent results over many years and should not be abandoned (see Figure 1 and Video 1). In fact, it is our clinical experience that late dilatation of the Carrel patches of the head vessels leading to so-called patch aneurysms is quite uncommon. As is known from pathology, arterial branch points are reinforced by extra collagenous fibers (a sort of biological rebar), ${ }^{6,7}$ and this may be the reason that the patch of aortic arch vessels is relatively dilatation-resistant. We recommend using a 2-vessel Carrel patch, which provides for a smaller suture line requiring less 

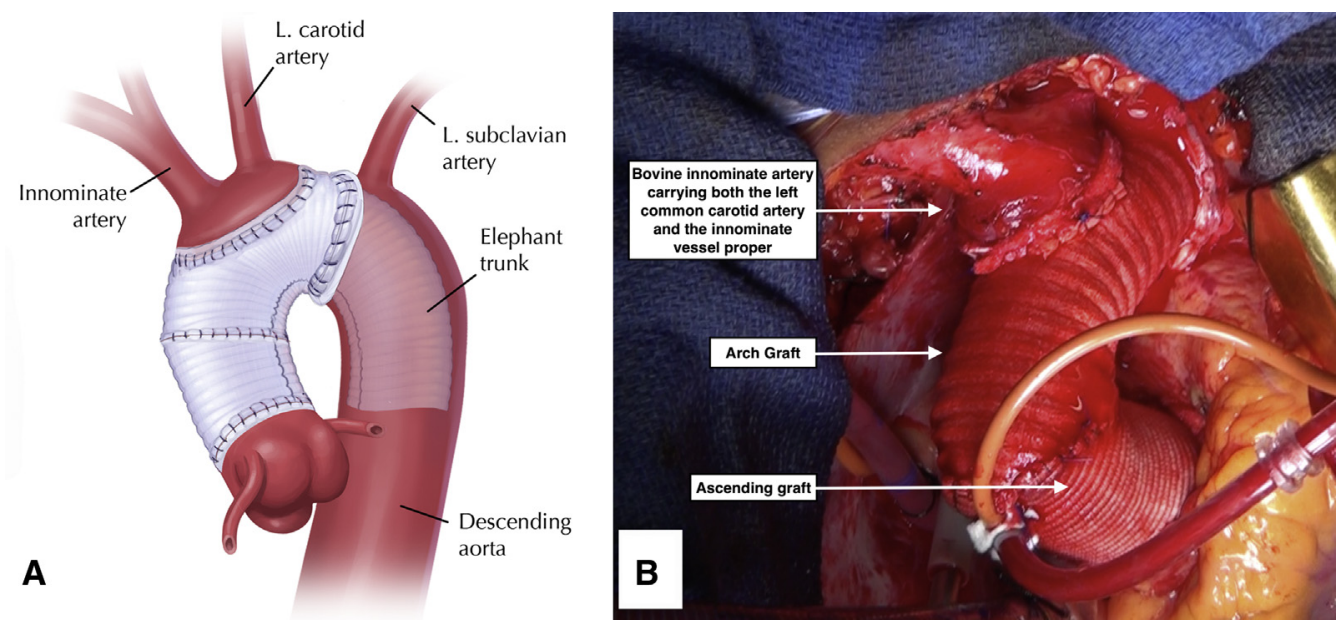

FIGURE 1. Aortic arch replacement with a 2-vessel Carrel patch reimplantation. A, Artist's rendition. B, Intraoperative image. Note that in the intraoperative image the innominate and left common carotid arteries have a common origin, which is known as the bovine aortic arch anomaly.

time for anastomosis completion and allows placement of the distal aortic anastomosis between the left carotid and left subclavian arteries. ${ }^{8}$ The left subclavian artery is very easily handled when the stage II elephant trunk procedure is performed several weeks later via left thoracotomy.

The authors' technique incurs periods of sequential interruption of perfusion of each of the 3 head vessels, at only moderate hypothermic levels and while they are actively rewarming. This may not be safe for the brain at the cellular level. The authors' clinical results would be best supplemented by quantitative neurologic studies to document that the brain is indeed well preserved with their techniques. By comparison, not only does straight deep hypothermic circulatory arrest yield excellent clinical and cerebral re-

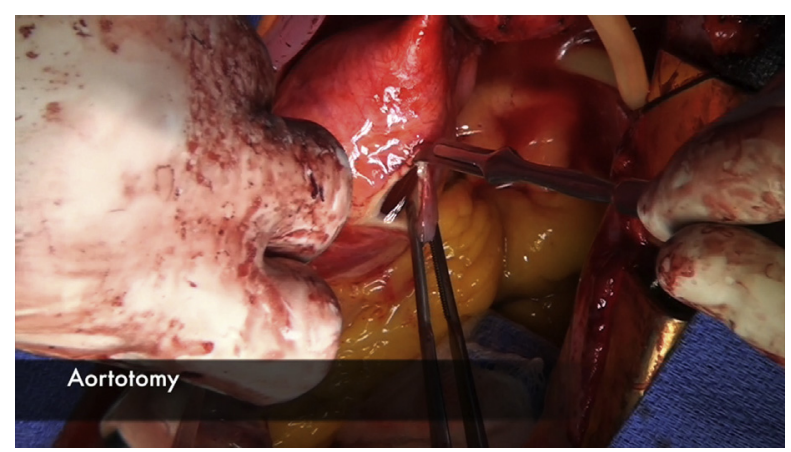

VIDEO 1. Two-vessel Carrel patch technique for aortic arch replacement. Video available at: https://www.jtcvs.org/article/S0022-5223(18)32963-5/ fulltext. sults, ${ }^{4,8}$ but also preservation of brain protection has been demonstrated quantitatively by extensive pre- and postoperative neuropsychometric testing. ${ }^{9,10}$

We thank Minatoya and colleagues ${ }^{1}$ for their important contribution to the aortic arch replacement literature.

\section{References}

1. Minatoya K, Inoue Y, Sasaki H, Tanaka H, Seike Y, Oda T, et al. Total arch replacement using a 4-branched graft with antegrade cerebral perfusion. J Thorac Cardiovasc Surg. 2019;157:1370-8.

2. Ma WG, Zhu JM, Zheng J, Liu YM, Ziganshin BA, Elefteriades JA, et al. Sun's procedure for complex aortic arch repair: total arch replacement using a tetrafurcate graft with stented elephant trunk implantation. Ann Cardiothorac Surg. 2013;2:642-8.

3. Ma WG, Zheng J, Zhang W, Sun K, Ziganshin BA, Wang LF, et al. Frozen elephant trunk with total arch replacement for type A aortic dissections: does acuity affect operative mortality? J Thorac Cardiovasc Surg. 2014;148:963-72.

4. Gega A, Elefteriades JA, Johnson MA, Tranquilli M, Farkas EA, Elefteriades JA. Straight deep hypothermic arrest: experience in 394 patients supports its effectiveness as a sole means of brain preservation. Ann Thorac Surg. 2007;84:759-66.

5. Spielvogel D, Kai M, Tang GHL, Malekan R, Lansman S. Selective cerebral perfusion: a review of the evidence. J Thorac Cardiovasc Surg. 2013; 145(Suppl):S59-62.

6. Kwon GP, Schroeder JL, Amar MJ, Remaley AT, Balaban RS. Contribution of macromolecular structure to the retention of low-density lipoprotein at arterial branch points. Circulation. 2008;117:2919-27.

7. Finlay HM, Whittaker P, Canham PB. Collagen organization in the branching region of human brain arteries. Stroke. 1998;29:1595-601.

8. Ziganshin BA, Rajbanshi RG, Tranquilli M, Fang H, Rizzo JA, Elefteriades JA. Straight deep hypothermic circulatory arrest for cerebral protection during aortic arch surgery: safe and effective. J Thorac Cardiovasc Surg. 2014;148:888-900.

9. Chau KH, Friedman T, Tranquilli M, Elefteriades JA. Deep hypothermic circulatory arrest effectively preserves neurocognitive function. Ann Thorac Surg. 2013;96:1553-9.

10. Percy A, Widman S, Rizzo JA, Tranquilli M, Elefteriades JA. Deep hypothermic circulatory arrest in patients with high cognitive needs: full preservation of cognitive abilities. Ann Thorac Surg. 2009;87:117-23. 